CLINICAL STUDY

\title{
Recurrence of hyperparathyroidism; a long-term follow-up after surgery for primary hyperparathyroidism
}

\author{
Gunilla Hedbäck and Anders Odén ${ }^{1}$ \\ Department of Surgery, Sahlgrenska University Hospital, Göteborg SE-413 45, Sweden and ${ }^{1}$ Department of Mathematics and Statistics, \\ Göteborg University, Göteborg, Sweden \\ (Correspondence should be addressed to G Hedbäck; Email: g.hedback@home.se)
}

\begin{abstract}
Objective: In general it is thought that recurrence of primary hyperparathyroidism is a rare event. To our knowledge, however, only one large patient series has been reported with a mean of more than 7 years of follow-up. The aim of the present study was to determine the long-term recurrence rate in 785 out of 886 patients operated on for primary hyperparathyroidism and followed-up for a mean of 10.03 years after surgery.

Design: Medical records were scrutinised. The patients who were still alive answered a questionnaire and had laboratory tests.

Methods: Follow-up data concerning the state of health, medical treatment, other diagnoses, renal function, and serum calcium and creatinine levels were found in the medical records of 203 patients, and were registered at the start of investigation of 582 patients. Intact parathyroid hormone values were determined in 252 patients. Recurrence rate and 95\% confidence interval (C.I.) were calculated. Results: Recurrence rate of hyperparathyroidism with constant or intermittent hypercalcaemia $(n=39)$ was $4.97 \%(95 \%$ C.I. $=3.45-6.74 \%)$ during a mean of 10 years of follow-up. Nine out of 39 had elevated serum creatinine levels. Recurrence rate of hyperparathyroidism with normal serum creatinine levels, including patients with normocalcaemia, intermittent hypercalcaemia, and constant hypercalcaemia was estimated to be $7-8 \%$ during a mean of 10 years of follow-up. Conclusions: Recurrence rate was determined with reasonable precision in this large patient series, and recurrence of hyperparathyroidism cannot be considered to be extremely rare, but it may occur more than 20 years after treatment in both single and multiple gland disease.
\end{abstract}

European Journal of Endocrinology 148 413-421

\section{Introduction}

Most surgeons recommend surgery for primary hyperparathyroidism and also in mild and asymptomatic disease (1). But how sure can we be, when we say that after surgery hypercalcaemia will not further trouble the patient? Previous long-term follow-up studies of large patient series were published in 1986 (2) with a mean follow-up of 7.7 years, and in 1992 (3) with a mean follow-up of 14.2 years. Both studies emanated from Uppsala, Sweden and provided detailed information about the patients in $70 \%$ and $58 \%$ of the cases respectively. The aim of the present study was to determine the recurrence rate of hyperparathyroidism after surgical treatment in a long time perspective, and with high precision, by using a large patient series with close to $90 \%$ follow-up, including determination of $95 \%$ confidence interval (C.I.).

\section{Patients and methods}

All patients operated on for primary hyperparathyroidism at Sahlgrenska Hospital in the years 1953-1982 were followed-up at the end of $1986(n=896)$ (4). Bilateral neck exploration had generally been performed at surgery. In a few cases, the indication for surgery had been goitre or thyroid tumour combined with hypercalcaemia of probable parathyroid origin. Hyperparathyroidism was histopathologically verified in all cases, and 754 patients had single gland disease, 140 multiple gland disease out of which 12 patients had multiple endocrine neoplasia, and two patients had parathyroid cancer according to the medical records at the end of 1982 (4). The latter two were excluded from the present follow-up.

For the diseased patients, medical records from the period after the operation at Sahlgrenska Hospital were 
sought and data were registered concerning the state of health, medical treatment, diagnoses, renal function, laboratory examinations when taken, together with year and date of the last observation found, and whether it was from an emergency situation or from a period of terminal care. The patients who were alive $(n=600)$ were contacted by letter containing an invitation to take part in a follow-up programme including a questionnaire, blood pressure measurement and blood tests. Six patient groups $(0-V)$ were defined. Group 0 consisted of eight patients who died within 1 month after surgery (4). Group I was patients followed-up at Sahlgrenska Hospital and group II was patients followed-up outside Göteborg. Group III was patients who had died but whose medical records contained accurate information and also patients who were alive but who were unwilling to take a full part in the follow-up, although they answered the questions and the laboratory values found in their medical records were used. Group IV consisted of patients who were alive but with whom we did not succeed in making contact. Group V was the deceased whose medical records lacked laboratory data or were not found. The study patients were those of groups I, II and III.

The laboratory tests carried out in group I were total serum calcium, serum creatinine, serum thyroxine, ionised serum calcium and serum parathyroid hormone concentrations using the immunoradiometric assay (IRMA) described below. The patients in group II received a note of admission to their local medical unit for serum calcium and creatinine determinations. Reference limits varied slightly between different laboratories for the lower limit for serum calcium $(2.10-2.20 \mathrm{mmol} / \mathrm{l})$ and the upper limit for serum creatinine $(110-125 \mu \mathrm{mol} / \mathrm{l})$. The reference limits in Sahlgrenska Hospital laboratory for total serum calcium were $2.20-2.60 \mathrm{mmol} / \mathrm{l}$, for ionised serum calcium $1.18-1.31 \mathrm{mmol} / \mathrm{l}$ and for serum creatinine $<120 \mu \mathrm{mol} / \mathrm{l}$ for males and $<110 \mu \mathrm{mol} / \mathrm{l}$ for females. The determination of serum parathyroid hormone concentrations at Sahlgrenska Hospital was performed using a radioimmunoassay (RIA; reference limit $<9.6 \mathrm{pmol} / \mathrm{l}$ ), but the IRMA (reference limits 10$65 \mathrm{ng} / \mathrm{l}$ ) was used for the determination of intact parathyroid hormone (5).

It was decided from the beginning that one checkup would be sufficient for patients with serum calcium levels below $2.50 \mathrm{mmol} / \mathrm{l}$, while further blood sampling was recommended for patients with levels of $2.50 \mathrm{mmol} / \mathrm{l}$ or above. These tests included, for group I, total serum calcium level, serum ionised calcium level and serum parathyroid hormone level according to the RIA and, for group II, total serum calcium level on three different occasions. However, parathyroid hormone levels were also determined in a few patients in group II, the decision being made by the home clinic.
Follow-up time for the patients was the time-period from surgery to when the first follow-up samples were taken, recorded by year and month. When complementary samples were collected, the true follow-up time was therefore somewhat longer, although no data were included after 1990. For group III, follow-up time was the time-period from surgery to the last occasion on which serum calcium and creatinine determinations were made.

For each patient it was evaluated whether recurrence of hyperparathyroidism, either primary or secondary, was likely to have occurred. All re-operations were considered, as well as the situation at follow-up. When constant or intermittent hypercalcaemia was found it was evaluated whether or not it was of parathyroid origin. A cure after parathyroid surgery was defined as serum calcium concentrations of $<2.55 \mathrm{mmol} / \mathrm{l}$ during the first postoperative year (4). When a cure was not achieved re-operation was generally performed, although exceptions were made. Patients considered to have persistent disease were clearly identified (4) in order not to be included among the cases with recurrent disease.

The risk of recurrence of hypercalcaemia, constant or intermittent, due to primary or secondary hyperparathyroidism during the follow-up period was estimated, and 95\% C.I. was calculated exactly by using binomial distribution (6). The risk of recurrent hyperparathyroidism with serum calcium above $2.75 \mathrm{mmol} / \mathrm{l}$ was also estimated, as was the risk of recurrent disease with normal serum creatinine value at follow-up.

In group I, the percentage of patients with high or elevated parathyroid hormone levels, normal serum creatinine levels and serum calcium levels within 2.30 to $2.60 \mathrm{mmol} / \mathrm{l}$ was determined, estimating the frequency of patients with probable normocalcaemic hyperparathyroidism at follow-up.

\section{Results}

The 894 patients were divided into the six groups defined above as shown in Table 1. As eight patients died within 1 month only 886 were available for long-term follow-up. Precise follow-up values of the serum calcium level a long time after surgery were achieved in 785 cases altogether $(88.6 \%)$.

Mean follow-up time was 10.03 years (S.D. 6.04). The distribution of follow-up years of the three groups is shown in Fig. 1. There were 30 patients followed-up for less than a year, all in group III. Mean follow-up time, mean age at follow-up, and mean serum calcium level from the first test occasion at follow-up are shown in Table 2. The distribution of these serum calcium levels are shown in Fig. 2. There were 32 out of 785 patients $(4.07 \%)$ with serum calcium $>2.60 \mathrm{mmol} / \mathrm{l}$ (Table 2). Eight of them had persistent hyperparathyroidism. In group I, one patient with a low parathyroid 
Table 1894 patients operated on for primary hyperparathyroidism were divided into six groups depending on how follow-up turned out at the end of 1986. Follow-up values of serum calcium were available only for the patients of groups I-III (785 patients).

\begin{tabular}{|c|c|c|c|c|c|c|c|}
\hline \multirow[b]{2}{*}{ Group } & \multirow[b]{2}{*}{ Definition } & \multirow[b]{2}{*}{$n$} & \multirow[b]{2}{*}{$\%$} & \multirow[b]{2}{*}{$\mathbf{M} / \mathbf{F}$} & \multicolumn{3}{|c|}{ Year of surgery } \\
\hline & & & & & IQR $25 \%$ & Median & IQR 75\% \\
\hline 0 & Died within 1 month after surgery & 8 & 0.9 & $1 / 7$ & 1965 & 1968 & 1973 \\
\hline I & Followed-up at Sahlgrenska Hospital & 278 & 31.1 & $53 / 225$ & 1972 & 1977 & 1980 \\
\hline II & Followed-up outside Göteborg & 304 & 34.0 & $76 / 228$ & 1970 & 1975 & 1979 \\
\hline III & Data on Ca levels found in medical records & 203 & 22.7 & $80 / 123$ & 1965 & 1969 & 1975 \\
\hline IV & Alive - declined check-up, abroad or lost & 16 & 1.8 & $6 / 10$ & 1972 & 1975 & 1979 \\
\hline $\mathrm{V}$ & Deceased; no late Ca values available & 85 & 9.5 & $22 / 63$ & 1970 & 1972 & 1976 \\
\hline
\end{tabular}

$M$, male; F, female; IQR, interquartile range.

hormone concentration (15 ng/l (IRMA)) had thyrotoxicosis, and her serum calcium level became normal after treatment. In another patient, a myeloma was diagnosed. Two patients, one in group II and one in group III, had terminal hypercalcaemia because of metastatic colonic cancer. Hence, expected or individual explanations for hypercalcaemia at follow-up were found in 12 out of 32 cases altogether. In group III, five patients were noted who had been investigated because of recurrent hypercalcaemia and explanations other than hyperparathyroidism had been found: thiazide treatment, a benign paraganglioma, breast cancer, a vertebral metastasis of medullary thyroid cancer, and mediastinal sarcoidosis.

Surgery for recurrent disease had been performed in 16 out of 785 patients $(2.04 \%)$, seven patients in group I, seven in group II and two in group III. In eight of them the serum calcium level at recurrence had not exceeded $2.75 \mathrm{mmol} / \mathrm{l}$. Four of these 16 patients had two recurrences, all with several years of normocalcaemia in between: one patient had a second adenoma removed after 15.1 years and 7 years later at follow-up had elevated serum calcium and parathyroid hormone levels (Table 3). The second patient had multiple

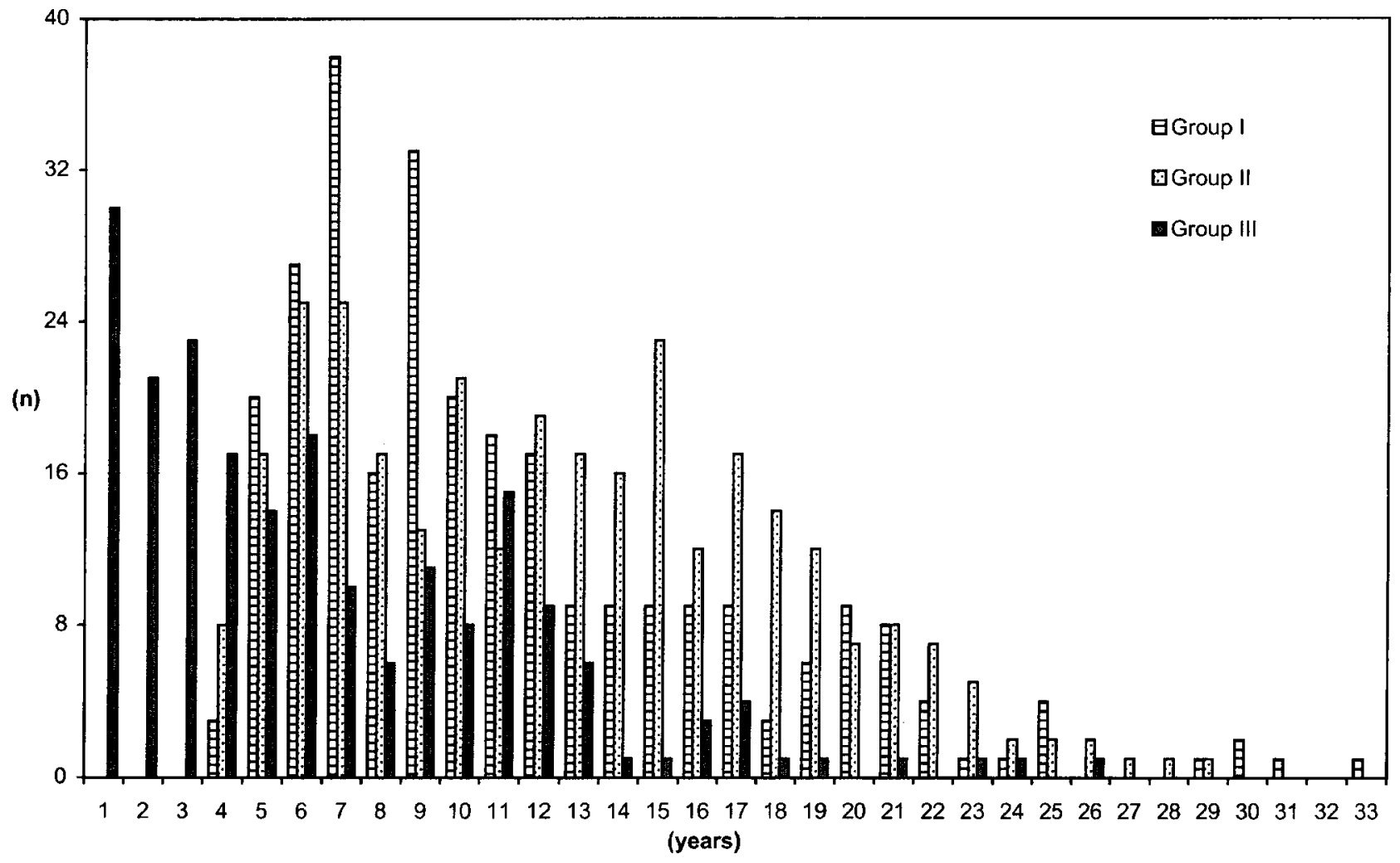

Figure 1 Numbers of patients operated on for primary hyperparathyroidism and followed-up 0-33 years after surgery. Group I was 278 patients followed-up in Göteborg, group II was 304 patients followed-up outside Göteborg, and group III was patients whose follow-up data were found in medical records, ten of whom were alive and 193 who had died. Mean follow-up time $(n=785)$ was 10.03 years (S.D. 6.04). Only patients in group III were followed-up for less than 3 years. 
Table 2 Result of follow-up of 785 patients operated on for primary hyperparathyroidism in 1953-82, mean follow-up time, mean age and serum calcium concentration taken at the first occasion of follow-up for groups I and II, and the last occasion for group III. The numbers of patients whose serum calcium level was below 2.20 and above $2.60 \mathrm{mmol} / \mathrm{l}$ in the different groups are given.

\begin{tabular}{|c|c|c|c|c|c|c|}
\hline \multirow[b]{2}{*}{$\begin{array}{l}\text { Group } \\
(n)\end{array}$} & \multirow{2}{*}{ 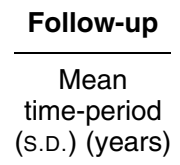 } & \multicolumn{2}{|c|}{ Age at follow-up } & \multicolumn{3}{|c|}{ Ca values at follow-up } \\
\hline & & $\begin{array}{c}\text { Mean age at } \\
\text { follow-up (S.D.) } \\
\text { (years) }\end{array}$ & $\begin{array}{l}\text { Range } \\
\text { (years) }\end{array}$ & $\begin{array}{l}\text { Mean (S.D.) } \\
(\mathrm{mmol} / \mathrm{l})\end{array}$ & $\begin{array}{c}\text { No. }(\%) \text { of } \\
\text { patients with } \\
<2.20 \mathrm{mmol} / \mathrm{l}\end{array}$ & $\begin{array}{c}\text { No. }(\%) \text { of } \\
\text { patients with } \\
>2.60 \mathrm{mmol} / \mathrm{l}\end{array}$ \\
\hline I (278) & $10.73(5.70)$ & $68.6(11.1)$ & $20.1-92.4$ & $2.37(0.17)$ & $22(7.9)$ & $13(4.7)$ \\
\hline II (304) & 11.99 (5.62) & $63.9(12.7)$ & $18.9-93.9$ & $2.37(0.14)$ & $15(4.9)$ & $15(4.9)$ \\
\hline III (203) & $6.00(5.10)$ & 68.9 (11.1) & $19.5-88.9$ & $2.31(0.17)$ & $32(15.8)$ & $4(2.0)$ \\
\hline All (785) & $10.03(6.04)$ & $66.9(11.8)$ & $18.9-93.9$ & $2.36(0.16)$ & $69(8.8)$ & $32(4.1)$ \\
\hline
\end{tabular}

endocrine neoplasia, with 7.7 and 6.1 years between the operations. The third patient had a parathyroid adenoma removed, part of which was implanted at surgery for goitre, but 4 years thereafter hypercalcaemia recurred. Most of the implanted tissue was excised and serum calcium normalised. At follow-up, however, both serum calcium and parathyroid hormone levels were marginally increased (Table 3). The fourth patient had a parathyroid adenoma removed at thyroidectomy because of papillary thyroid cancer and the other three glands were implanted in the neck muscles. Four years later hypercalcaemia recurred, hyperplastic parathyroid tissue was excised from the muscle and her serum calcium levels became normal. However, at follow-up, it seemed as if a recurrence of hyperparathyroidism was about to become noticeable again (Table 3).

Two patients undoubtedly had secondary hyperparathyroidism at recurrence. Another two had slightly elevated serum creatinine levels $(130-140 \mu \mathrm{mol} / \mathrm{l})$ at surgery for their recurrences, which were still considered to be of the primary kind. In one patient with water clear cell hyperplasia, another hyperplastic

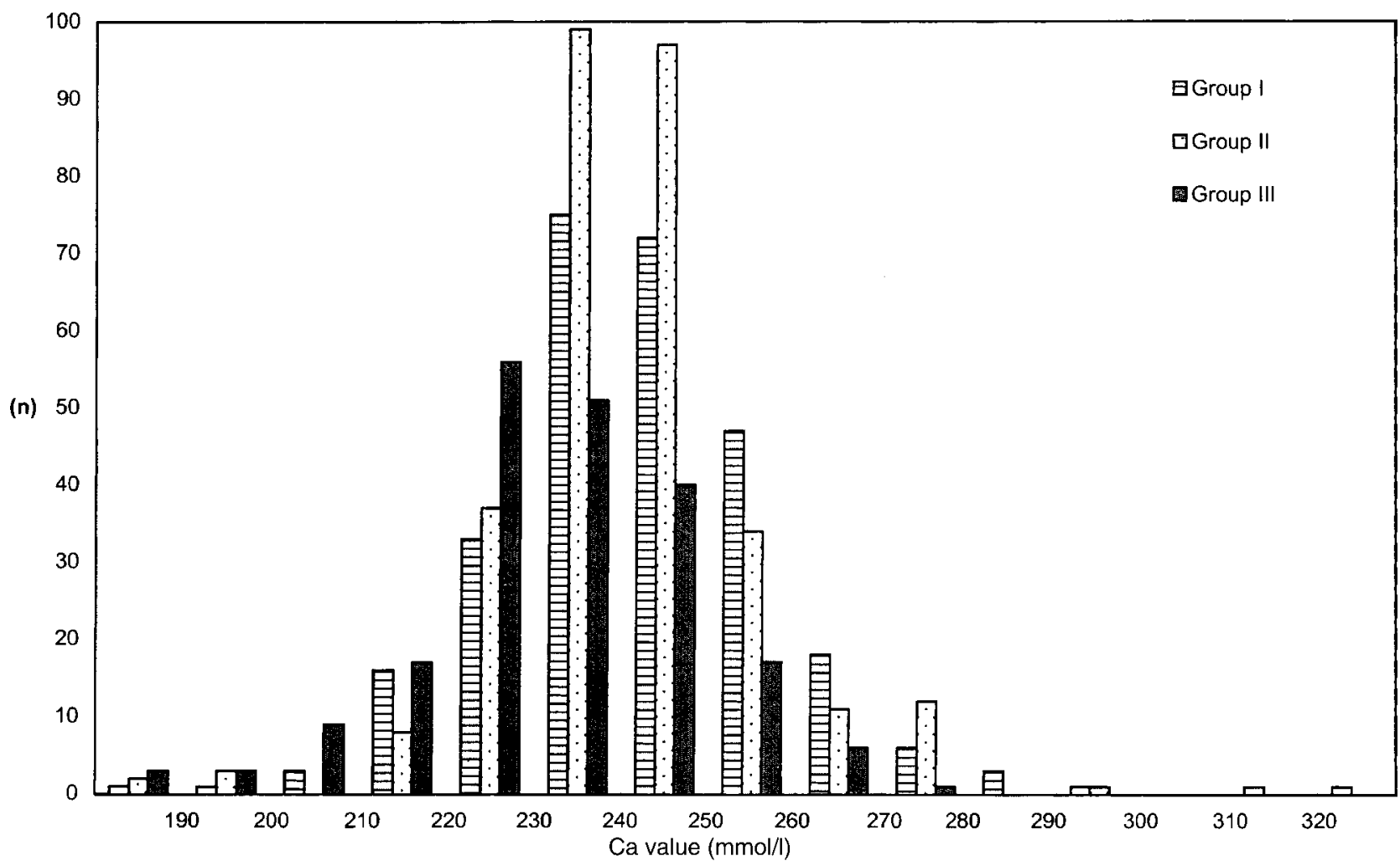

Figure 2 Distribution of total serum calcium levels taken at follow-up of 582 patients. Group I was followed-up in Göteborg ( $n=278$ ), group II was followed-up outside Göteborg $(n=304)$, and group III patients were those whose last serum calcium values were found in the medical records of 203 patients previously operated on for primary hyperparathyroidism. The bars represent the numbers of patients with serum calcium values within $10 \mathrm{mmol} / \mathrm{l}$ intervals from 1.80 to less than $1.90,1.90$ to less than $2.00 \mathrm{mmol} / \mathrm{l}$, up to 3.20 to less than $3.30 \mathrm{mmol} / \mathrm{l}$. 
Table 3 Thirteen patients out of 278 (group I) who at long-term follow-up after surgery for primary hyperparathyroidism (HPT) had laboratory data suggestive of recurrent disease; three patients had been treated for recurrent disease previously.

\begin{tabular}{|c|c|c|c|c|c|c|c|c|c|c|c|c|}
\hline Sex & $\begin{array}{l}\text { Year of } \\
\text { surgery }\end{array}$ & $\begin{array}{l}\text { Type } \\
\text { of } \\
\text { HPT }\end{array}$ & $\begin{array}{l}\text { Serum Ca at } \\
\text { follow-up } \\
(\text { mmol/l) }\end{array}$ & $\begin{array}{c}\text { Ionised } \\
\text { Ca } \\
(\mathrm{mmol} / \mathrm{l})\end{array}$ & $\begin{array}{l}\text { Serum } \\
\text { creatinine } \\
(\mu \mathrm{mol} / \mathrm{l})\end{array}$ & $\begin{array}{c}\text { PTH by } \\
\text { RIA } \\
(\mathrm{pmol} / \mathrm{l})\end{array}$ & $\begin{array}{l}\text { PTH by } \\
\text { IRMA } \\
\text { (ng/l) }\end{array}$ & $\begin{array}{c}\text { Age } \\
\text { (years) }\end{array}$ & $\begin{array}{l}\text { Follow- } \\
\text { up } \\
\text { (years) }\end{array}$ & $\begin{array}{l}\text { HPT status } \\
\text { at follow-up }\end{array}$ & $\begin{array}{l}\text { Patient's own health description } \\
\text { and summary of information given }\end{array}$ & $\begin{array}{l}\text { Hypertension CVD } \\
\text { (year of diagnosis) }\end{array}$ \\
\hline$M$ & 1953 & MgID & $2.70 * / 2.70^{*}$ & 1.31 & $140^{*}$ & 5.8 & 40 & 77 & 33.2 & $\mathrm{Rec}^{*} \mathrm{Ca}:+$ & $\begin{array}{l}\text { FINE, but dysuria, prostatic symptoms; } \\
\text { gout 1965; memory problems }\end{array}$ & ; Ht 1953 \\
\hline $\mathrm{M}$ & 1958 & MgID & $2.50 / 2.60$ & $1.41^{*}$ & 109 & 7.5 & 25 & 76 & 29.5 & Rec? Ca:+ & $\begin{array}{l}\text { FINE, after surgery for prostatic } \\
\text { hyperplasia; slight dizziness; no } \\
\text { medication }\end{array}$ & \\
\hline $\mathrm{F}$ & 1962 & MgID & $3.27 * / 3.30 *$ & $1.88^{*}$ & 108 & $40.0^{*}$ & Missing & 76 & 24.2 & Rec* Ca:+++ & $\begin{array}{l}\text { OK, but anxiety, dysuria; gout 1966; } \\
\text { medication with diuretic }\end{array}$ & Ht CVD \\
\hline $\mathrm{F}$ & $\begin{array}{l}1965 \\
1980\end{array}$ & $\begin{array}{l}\mathrm{Ad} \\
\mathrm{Ad}\end{array}$ & $2.7 \star / 2.8^{*}$ & $1.40^{*}$ & $189^{*}$ & $24.1^{*}$ & $139 *$ & 68 & $\begin{array}{r}15.1 \\
7.0\end{array}$ & $\mathrm{Rec}^{\star} \mathrm{Ca}:++$ & $\begin{array}{l}\text { OK, but anxiety, cardiac angina; } \\
\text { hypertension }\end{array}$ & Ht 1973 CVD 1981 \\
\hline $\mathrm{F}$ & 1971 & SgID & $2.60 / 2.50$ & $1.35^{*}$ & $125^{*}$ & 3.1 & 25 & 73 & 5.0 & Rec? Ca:+ & $\begin{array}{l}\text { OK, but monthly need of oesophageal } \\
\text { dilatations }\end{array}$ & \\
\hline $\mathrm{F}$ & 1971 & MgID & $2.50 / 2.50$ & $1.40^{*}$ & 73 & $12.4^{*}$ & $118^{*}$ & 73 & 15.2 & $\mathrm{Rec}^{\star} \mathrm{Ca}:+$ & $\begin{array}{l}\text { OK, but anxiety at times; medication } \\
\text { for arthralgia }\end{array}$ & Ht 1980 \\
\hline $\mathrm{F}$ & 1972 & SgID & $2.5 / 2.64^{\star}$ & $1.40^{*}$ & 75 & $12.7^{*}$ & $81^{*}$ & 47 & 14.7 & Rec* Ca:+ & FINE, normotension; no medication & \\
\hline $\mathrm{F}$ & 1975 & SgID & $2.70 * / 2.57 / 2.50$ & $1.39^{*}$ & 94 & 7.4 & 60 & 71 & 12.0 & $\mathrm{Rec}^{*} \mathrm{Ca}:+$ & $\begin{array}{l}\text { OK, but oesophageal reflux; no } \\
\text { medication }\end{array}$ & \\
\hline $\mathrm{F}$ & $\begin{array}{l}1979 \\
1983\end{array}$ & $\begin{array}{l}\text { Ad } \\
\text { Impl }\end{array}$ & $2.8^{\star} / 2.5$ & $1.33^{*}$ & 109 & $9.8^{*}$ & 46 & 79 & $\begin{array}{l}4.7 \\
3.2\end{array}$ & $\mathrm{Rec}^{\star} \mathrm{Ca}:+$ & FINE, but treatment for hypertension & Ht 1967 \\
\hline $\mathrm{F}$ & 1979 & SgID & $2.50 / 2.67^{\star}$ & $1.35^{\star}$ & 68 & $9.8^{*}$ & 37 & 63 & 7.8 & Rec* Ca:+ & $\begin{array}{l}\text { OK, but cardiac angina; orally treated } \\
\text { diabetes; lower leg fracture } 1982\end{array}$ & Ht 1978 CVD 1978 \\
\hline $\mathrm{F}$ & 1979 & SgID & $2.70 * / 2.30 / 2.50$ & 1.26 & 76 & 5.8 & Missing & 62 & 7.9 & Rec? Ca:m? & $\begin{array}{l}\text { OK, but hypertension; (repeated Ca } \\
\text { normal) }\end{array}$ & Ht 1978 \\
\hline $\mathrm{F}$ & $\begin{array}{l}1979 \\
1983\end{array}$ & $\begin{array}{l}\mathrm{Ad} \\
\mathrm{Hpl}\end{array}$ & $2.60 / 2.80 * / 2.50$ & Missing & 65 & 7.2 & 65 & 38 & $\begin{array}{l}4.3 \\
3.5\end{array}$ & Rec* Ca:+ & $\begin{array}{l}\text { UNWELL, lumbalgia and constant } \\
\text { headache }\end{array}$ & \\
\hline $\mathrm{F}$ & 1980 & SgID & $2.61 * / 2.66^{*}$ & $1.38^{*}$ & 106 & 6.2 & 35 & 76 & 6.8 & $\mathrm{Rec}^{*} \mathrm{Ca}:+$ & $\begin{array}{l}\text { OK, but anxiety; lithium treatment; } \\
\text { normotension }\end{array}$ & \\
\hline
\end{tabular}


gland was removed and, in the other, an adenoma was found both times. The latter was also found among the four patients with two recurrences, and her serum creatinine level at follow-up was $189 \mu \mathrm{mol} / \mathrm{l}$ (Table 3).

Surgically verified recurrent primary hyperparathyroidism occurred in multiple gland disease after a mean of 5.09 years (S.D. 2.76), and in patients primarily considered to have single gland disease after a mean of 11.43 years (S.D. 4.37).

In addition to the 16 re-operated patients, ten patients in group I (Table 3) and 13 in group II (Table 4) had intermittent or constant hypercalcaemia suggestive of recurrence of primary hyperparathyroidism at follow-up. There were 582 patients (groups I and II) who participated in the first part of the follow-up procedure and 126 in the second part. Another eight were asked to give complementary blood samples but did not turn up the second time, two from group II with hypercalcaemia shown in Table 4, another two from group II with serum calcium $(2.50 \mathrm{mmol} / \mathrm{l})$ and normal serum creatinine levels and four from group I where sufficient samples had been taken to consider recurrent disease unlikely. When the serum calcium level was near the upper reference limit and the parathyroid hormone level taken at the same time was not supressed, this was interpreted as signifying a recurrence. In consequence, there were ten cases of recurrent disease verified by elevated or unsuppressed parathyroid hormone levels, and three probable cases of recurrent disease in group I. But in group II only four patients had recurrent disease that was verified by laboratory tests or scintigraphy, and nine were considered to have probable recurrent disease. Two patients with parathyroid hormone levels of only $25 \mathrm{ng} / \mathrm{l}$ were classified as recurrent cases which was considered no less probable than other explanations for their high serum calcium values. The intact parathyroid hormone level of $35 \mathrm{ng} / \mathrm{l}$ in one patient with oral lithium therapy was also considered likely to indicate that hyperparathyroidism had caused her hypercalcaemia. The health descriptions of the patients of groups I and II are given in Tables 3 and 4 respectively. The 26 patients with probable recurrent disease at follow-up described their situations as 'fine' in ten cases, 'OK' in thirteen, and 'unwell' in three cases, although nine of them suffered from anxiety and sixteen had hypertension and/or cardiovascular disease.

There were 252 patients in group I whose parathyroid hormone values were available $(90.6 \%)$. In three of them the parathyroid hormone level was $>50 \mathrm{ng} / \mathrm{l}$ with serum calcium concentrations of $2.50-2.60 \mathrm{mmol} / \mathrm{l}$ and in five the hormone level was elevated with serum calcium levels of $2.30-2.60 \mathrm{mmol} / \mathrm{l}$. These eight patients had normal serum creatinine values. They were classified as patients with probable normocalcaemic hyperparathyroidism and the risk of this condition during a mean
10 years of follow-up was consequently 3.17\% (95\% C.I. $=1.01-6.16 \%$ ).

If all patients who had either been re-operated or had laboratory data suggestive of recurrent hyperparathyroidism with hypercalcaemia were counted, then recurrence occurred in 39 out of 785 patients during a mean 10 years of follow-up, and recurrence rate was $4.97 \%$ $(95 \%$ C.I. $=3.45-6.74 \%)$. There were $16 / 39$ patients who had serum calcium $>2.75 \mathrm{mmol} / \mathrm{l}$ at least once at diagnosis of recurrent disease which was $2.04 \%$ (95\% C.I. $=1.05-3.30 \%)$. Recurrent disease with normal serum creatinine value at follow-up occurred in 30 patients out of 785 , or in $3.82 \%$ of the cases $(95 \%$ C.I. $=2.48-5.41 \%$ ).

\section{Discussion}

We found recurrence of constant or intermittent hypercalcaemia of probable parathyroid origin in $4.97 \%$ of the patients during a mean of 10 years of follow-up. The present long-term follow-up of 785 patients operated on for primary hyperparathyroidism is, to our knowledge, the largest of its kind, and the follow-up time of a mean of 10.03 years is long enough for adequate evaluation. The previous long-term follow-up studies mentioned herein were performed in Uppsala. One reported on total serum calcium of 416 patients operated on in 1956-1979 after a mean of 7.7 years (2). Late recurrences were found in both multiple and single gland disease, but the former tended to recur earlier, as in the present study. The other more recent Uppsala study by Lundgren et al. (3) included partly the same patients. Serum calcium and serum creatinine values were determined in 410 patients and parathyroid hormone values in 179 of them. After a mean of 14.2 years the risk of recurrent hypercalcaemic disease was $8.3 \%$ which, together with our results, may indicate a time-dependent increase in recurrence rate. Their 95\% C.I., when calculated as in the present study, was $5.6-11.4 \%$ which is a rather wide interval. It is obvious that a larger number of patients is essential to obtain high precision, and the substantially smaller 95\% C.I. calculated from the series of 785 patients was considered satisfactory, while that of 252 patients was relatively wider. It is not a coincidence that these two long-term follow-up studies emanated from Sweden: our medical care is organised in a geographically centralised fashion, and we have a national population registry with which any individual can easily be traced, circumstances which facilitate the management of long-term follow-up studies. Other large patient series reported from other countries contained fewer patients with shorter follow-up periods, or fewer data available: Bruining et al. (7) reported on 582/615 patients followed for a mean of 5.6 years, Russel \& Edis (8) on $461 / 500$ followed-up for $0-6$ years, Sivula \& Ronni-Sivula (9) on $289 / 334$ patients who 
Table 4 Thirteen patients out of 304 (group II) who at long-term follow-up after surgery for primary hyperparathyroidism (HPT) had laboratory data suggestive of recurrent disease; three patients had been treated for recurrent disease previously.

\begin{tabular}{|c|c|c|c|c|c|c|c|c|c|c|}
\hline Sex & $\begin{array}{l}\text { Year of } \\
\text { surgery }\end{array}$ & $\begin{array}{l}\text { Type } \\
\text { of } \\
\text { HPT }\end{array}$ & $\begin{array}{l}\text { Serum Ca at } \\
\text { follow-up } \\
\text { (mmol/l) }\end{array}$ & $\begin{array}{l}\text { Serum } \\
\text { creatinine } \\
(\mu \mathrm{mol} / \mathrm{l})\end{array}$ & $\begin{array}{l}\text { Parathyroid } \\
\text { investigation }\end{array}$ & $\begin{array}{c}\text { Age } \\
\text { (years) }\end{array}$ & $\begin{array}{c}\text { Follow- } \\
\text { up } \\
\text { (years) }\end{array}$ & $\begin{array}{l}\text { HPT status } \\
\text { at follow-up }\end{array}$ & $\begin{array}{l}\text { Patient's own health description and } \\
\text { a summary of information given }\end{array}$ & $\begin{array}{l}\text { Hypertension CVD; } \\
\text { year of diagnosis }\end{array}$ \\
\hline $\mathrm{F}$ & 1962 & SglD & $2.74^{\star} / 2.62^{\star} / 2.80^{\star}$ & 74 & $\begin{array}{l}10^{*}(\mathrm{pmol} / / \\
\mathrm{RIA})\end{array}$ & 70 & 24.8 & $\mathrm{Rec}^{\star} \mathrm{Ca}:++$ & $\begin{array}{l}\text { FINE, but breast cancer in 1977, myocardial } \\
\text { infarction in } 1981\end{array}$ & Ht 1980 CVD 1981 \\
\hline $\mathrm{F}$ & 1964 & SglD & $2.76^{*}$ & $453^{*}$ & \multirow[t]{5}{*}{$\begin{array}{l}\text { Scintigraphy: } \\
\text { left lower gland }\end{array}$} & 67 & 22.6 & $\mathrm{Rec}^{\star} \mathrm{Ca}:++$ & $\begin{array}{l}\text { UNWELL, dysuria; cardiac angina; } \\
\text { Colles fracture in } 1984\end{array}$ & Ht 1968 CVD 1985 \\
\hline M & 1966 & SglD & $2.77 * / 2.44 / 2.48 / 2.55$ & $126^{*}$ & & 72 & 20.3 & Rec? Ca:+ & OK, but anxiety at times; ulcer disease & Ht 1975 \\
\hline $\mathrm{F}$ & 1966 & MgID & $2.71 \star / 2.60 / 2.57$ & 100 & & 71 & 20.3 & Rec? Ca:+ & FINE, no medication; Colles fracture in 1977 & \\
\hline $\mathrm{F}$ & 1970 & SglD & $2.60 / 3.00 * / 2.60$ & 55 & & 82 & 16.4 & Rec? Ca:++ & $\begin{array}{l}\text { OK, anxiety; asthma; dyspepsia; hypertensive } \\
\text { drugs inadequate }\end{array}$ & Ht 1949 \\
\hline $\mathrm{F}$ & 1972 & SglD & $2.7 * / 2.6 / 2.5 / 2.6$ & 67 & & 62 & 14.9 & Rec? Ca:+ & $\begin{array}{l}\text { FINE, cardiac medication with digitalis and } \\
\text { diuretics }\end{array}$ & $\mathrm{Ht}$ ? CVD \\
\hline $\mathrm{F}$ & 1973 & MglD & $2.75^{\star} / 2.73^{\star} / 2.67^{\star}$ & 102 & \multirow[t]{5}{*}{ Increased* } & 60 & 13.8 & $\mathrm{Rec}^{\star} \mathrm{Ca}:++$ & OK, but anxiety at times; treatment for gout & Ht 1983 \\
\hline $\mathrm{F}$ & 1974 & SglD & $2.70 \star / 2.60 / 2.50 / 2.60$ & $119^{*}$ & & 75 & 12.9 & Rec? Ca:+ & $\begin{array}{l}\text { UNWELL, but anxiety at times; aching legs; } \\
\text { diabetes from 1972; cerebrovascular lesion in } 1987\end{array}$ & Ht 1955 CVD? \\
\hline $\mathrm{F}$ & 1974 & SglD & $2.7 * / 2.3 / 2.4 / 2.3$ & 95 & & 33 & 12.4 & Rec? Ca:m? & FINE, had a renal stone in 1977; no medication & \\
\hline $\mathrm{F}$ & 1977 & MgID & $2.65^{\star} / 2.71^{*}$ & 48 & & 46 & 9.3 & Rec? Ca:+ & $\begin{array}{l}\text { OK, but immobilised because of muscle } \\
\text { dystrophia; died in } 1987 \text { from thromboembolic } \\
\text { disease }\end{array}$ & \\
\hline $\mathrm{F}$ & 1980 & SglD & $2.7 * / 2.5 / 2.6 / 2.4$ & 77 & & 74 & 6.8 & Rec? Ca:+ & FINE, treatment with diabetes diagnosed in 1986 & Ht 1979 CVD 1979 \\
\hline $\mathrm{F}$ & 1980 & MgID & $2.70 \star / 2.50 / 2.60$ & 80 & \multirow[t]{2}{*}{$\begin{array}{l}10.8^{*}(\mathrm{pmol} / \mathrm{l} ; \\
\mathrm{RIA})\end{array}$} & 66 & 6.2 & $\mathrm{Rec}^{\star} \mathrm{Ca}:+$ & $\begin{array}{l}\text { OK, urinary tract infection in } 1983-84 \\
\text { worries a lot; no drugs }\end{array}$ & \\
\hline M & 1981 & MgID & $2.61^{\star}$ & 86 & & 70 & 5.7 & Rec? Ca:m & $\begin{array}{l}\text { FINE, treatment for hypertension (did not } \\
\text { give more samples) }\end{array}$ & Ht 1978 \\
\hline
\end{tabular}

See Table 3 for abbreviations. 
were followed for approximately a mean of 5 years after surgery, van Heerden et al. (10) on 322/384 patients followed for a mean of 4 years, Proye et al. (11) on $190 / 304$ patients followed for a mean of 7.4 years and Carneiro \& Irvin (12) who reported on 320 patients followed for a mean of 6.2 years.

Follow-up values of serum calcium were, in the present study, missing for 101 patients (11\%). Most of the patients lost to follow-up had died (85/284) and there were difficulties in finding very old medical records. In contrast, follow-up of our living patients was more successful with 582 out of 600 patients (97\%). Two patients had emigrated and were not found, ten lived abroad, four declined to participate, and two answered the questionnaire only. We consider it unlikely that the rather moderate number of patients lost to follow-up would have had a considerably different risk of recurrence compared with the number of patients studied, and thereby to substantially affect the outcome of the study.

Analysis of total serum calcium concentration may vary between laboratories, and may also vary from time to time in one individual, especially in patients with primary hyperparathyroidism (13). Altogether, 68 total serum calcium determinations were performed in the 26 patients with probable recurrent disease, but only 38 out of 68 values were elevated $(47.1 \%)$. Less than one-third of the 24 patients with probable recurrent hyperparathyroidism, and who had more than one serum calcium value taken, had constant hypercalcaemia $(n=7)$. Not only is hyperparathyroidism often symptomless, it is obviously also difficult to detect in spite of serum calcium analyses being taken, as intermittent hypercalcaemia appears to be more frequent than constant hypercalcaemia. Our procedure of taking further samples in patients with serum calcium $\geq 2.50 \mathrm{mmol} / \mathrm{l}$ was aimed at increasing the chance of identifying as many patients as possible with intermittent hypercalcaemia. A few such patients may still have escaped identification. This risk of undetected recurrent cases with intermittent hypercalcaemia would be compensated for by the study of group I to determine the risk of recurrent hyperparathyroidism with normocalcaemia and normal serum creatinine. It is probable that these patients may have hypercalcaemia occasionally, but they did not have it when the tests were taken.

A few of the 26 patients with probable recurrent disease may be evaluated as borderline cases, but we found it wiser to include them all and account for them, and allow the reader to make the decision. On the other hand, repeated recurrences found in four patients were registered as only four recurrences in the calculations.

We found that recurrent hyperparathyroidism was generally primary in contrast to secondary. Thirty patients out of 785 (3.8\%) had signs of probable recurrent primary disease as their serum creatinine levels were normal. Five patients shown in Tables 3 and 4 had slightly elevated serum creatinine values. It is possible that some clinicians would suggest secondary disease to be the probable reason for their recurrence, but in view of the findings at surgery in other patients with similar situations, two described above, and several more observed in the clinic (4) it was not considered very probable. Another patient who previously had an adenoma removed had a substantially increased serum creatinine value $(453 \mu \mathrm{mol} / \mathrm{l})$ at follow-up, and she appeared, according to her scintigraphy, to have her recurrence in just a second diseased gland (Table 4), and therefore her recurrence was considered rather as primary hyperparathyroidism. The observed frequency of renal impairment, defined as elevated serum creatinine level, among patients with recurrence of hyperparathyroidism with constant or intermittent hypercalcaemia was, according to the above findings, nine out of 39 or $23 \%$. Two out of $39(5.1 \%)$ had confirmed secondary hyperparathyroidism with all glands hyperplastic, one with chronic nephritis, and the other without additional renal diagnosis determined. The total number of recurrent cases with normal renal function as evaluated by the serum creatinine level was 30 out of 785 or $3.82 \%$. Adding the frequency of probable normocalcaemic hyperparathyroidism $(3.17 \%)$, the overall risk of recurrence is $6.99 \%$, or close to $7 \%$ during a mean of 10 years of follow-up. Unfortunately vitamin D status was not investigated in the follow-up of these patients, making the diagnosis of primary disease versus secondary less certain. However, as mentioned above, a proportion of the patients with elevated serum creatinine levels was still considered to have primary disease, the consequence of which is that the recurrence rate of probable primary hyperparathyroidism during a mean of 10 years would be slightly higher than $7 \%$ or almost $8 \%$.

It is worth noting that the patients' own health descriptions were very positive, although more than half had hypertension with or without cardiovascular disease, and other kinds of discomfort occurred as well. In fact, only six patients out of $26(23 \%)$ with probable recurrent disease appeared to be truly 'fine'. It was beyond the subject of the present study to strictly evaluate this part of the follow-up results, but considering that these patients were 33-82 years old (mean 66.4 years) they might not be as fit as could be expected.

In summary, this study essentially confirmed previous findings on recurrence of hypercalcaemic hyperparathyroidism a long time after surgery for primary hyperparathyroidism $(2,3)$, although with a higher precision. We found the recurrence risk of hypercalcaemic hyperparathyroidism to be $5 \%$ with $95 \%$ C.I. of $3.5-6.7 \%$ during a mean of 10 years of follow-up, the risk of recurrence with substantial hypercalcaemia $(>2.75 \mathrm{mmol} / \mathrm{l})$ to be $2 \%$ and the risk of recurrence with constant hypercalcaemia to be approximately 
$1 \%$. These estimations concern recurrence of both primary and secondary hyperparathyroidism, although recurrence as secondary disease occurred in but a minority of the cases. If only patients with normal renal function and recurrent hyperparathyroidism, including cases with normocalcaemia, were considered, then the recurrence rate would be approximately $7 \%$. Recurrence may occur after more than 20 years as for both single and multiple gland disease.

\section{Acknowledgements}

We thank all colleagues who took care of and examined these patients at Sahlgrenska Hospital in 1952-1982, and especially Dr I Hedman, Dr L-E Tisell, Dr BBengtsson, Dr G Hansson, Nurse G Widell, Secretary B-I Gunnarsson and Chemist P-A Lundberg for their valuable help in collecting patient data.

\section{References}

1 Clark $\mathrm{OH}$. 'Asymptomatic' primary hyperparathyroidism: is parathyroidectomy indicated? Surgery $1994116947-953$.

2 Rudberg C, Åkerström G, Palmér M, Ljunghall S, Adami HO, Johansson $\mathrm{H}$ et al. Late results of operation for primary hyperparathyroidism in 441 patients. Surgery 1986 99 643-651.

3 Lundgren E, Rastad J, Ridefelt P, Juhlin C, Åkerström G \& Ljunghall S. Long-term effects of parathyroid operation on serum calcium and parathyroid hormone values in sporadic primary hyperparathyroidism. Surgery 1992112 1123-1129.

4 Hedbäck G, Tisell L-E, Bengtsson B-Å, Hedman I \& Odén A. Premature death in patients operated on for primary hyperparathyroidism. World Journal of Surgery 1990 14 829-836.
5 Nussbaum SR, Zahradnik RJ, Lavigne JR, Brennan GL, NozawaUng K, Kim LY et al. Highly sensitive two-site immunoradiometric assay of parathyrin, and its utility in evaluating patients with hypercalcemia. Clinical Chemistry 198733 1364-1367.

6 Lehmann EL. Confidence bounds. In Testing Statistical Hypotheses, edn 1, ch. 3.5, pp 78-83. New York: John Wiley \& Sons, 1959.

7 Bruining HA, van Houten H, Juttmann JR, Lamberts SWJ \& Birkenhäger JC. Results of operative treatment of 615 patients with primary hyperparathyroidism. World Journal of Surgery $1981585-90$.

8 Russell CF \& Edis AJ. Surgery for primary hyperparathyroidism: experience with 500 consecutive cases and evaluation of the role of surgery in the asymptomatic patient. British Journal of Surgery $198269244-247$.

9 Sivula A \& Ronni-Sivula H. Observations on 334 patients operated on for primary hyperparathyroidism. Annales Chirurgiae et Gynaecologiae $1985 \mathbf{7 4} 66-73$.

10 Van Heerden JA, Hon MB \& Grant CS. Surgical treatment of primary hyperparathyroidism: an institutional perspective. World Journal of Surgery 199115 688-692.

11 Proye C, Carnaille B, Quievreux JL, Combemale F, Oudar C \& Lecomte-Houcke M. Late outcome of 304 consecutive patients with multiple gland enlargement in primary hyperparathyroidism treated by conservative surgery. World Journal of Surgery 199822 529-530.

12 Carneiro DM \& Irvin GL III. Late parathyroid function after successful parathyroidectomy guided by intraoperative hormone assay (QPTH) compared with standard bilateral neck exploration. Surgery $2000 \mathbf{1 2 8} 925-929$.

13 Hedbäck G \& Odén A. Clinical evaluation of total serum calcium in primary hyperparathyroidism and the risk of death after surgery. European Journal of Clinical Investigation 199525 $48-52$.

Received 4 November 2002

Accepted 8 January 2003 